\title{
Energy Efficiency in Textile Sector of Pakistan: Analysis of Energy Consumption of Air-Conditioning Unit
}

\author{
Aftab Khan Masood, Sher Muhammad, Shazia Iftikhar, Hammad Altaf, Wasi Ullah, and Faisal Shabbir
}

\begin{abstract}
Pakistan today is facing a serious energy crisis due to the alarming depletion of energy resources and increasing demand of the industry, which has badly affected our industrial sector in general. No doubt, this situation has emerged globally, but this is also a fact that these energy crises in our industrial sector are due to orthodox processes, conventional infrastructures/buildings, inefficient HVAC systems, inadequate use of electrical and mechanical equipment, non compliance to standard inspection techniques which has resulted higher energy losses. This study reveal to the management of the factors, (i.e. housekeeping, control of operations and infrastructure), affecting the performance of $\mathrm{AC}$ plants of the spinning subsector of textile industry. Energy audits were conducted to collect data. The data was analyzed and it was concluded that along with the technological interventions we need to introduce green infrastructure in $\mathrm{AC}$ plants of spinning mills.
\end{abstract}

Index Terms - Energy efficiency, energy consumption, textile industry.

\section{INTRODUCTION}

Energy is an important factor which fulfills our basic needs like lighting, heating, cooking, transportation and also helps for the achievement of socioeconomic expansion objectives [1]. Due to latest industrial growth and expansion, energy consumption in established countries is exceptionally increasing.

For years, the balancing of Pakistan's supply against the demand for electricity has remained unresolved. This crisis appears as a barrier in the long-term future, unless proper implementation is assumed on priority basis. At the present, demand exceeds supply.

In order to reduce the greenhouse gas (GHG) emissions it is of the need to: establish awareness for energy consumption, increase energy efficiency and replace fossil fuels with renewable energy [2].

Rising energy costs and increasing demand make energy efficiency an absolute priority for Pakistan. It is the least-cost way of bridging the energy gap. The marginal cost of additional supply is much higher than the cost of investing in energy efficiency. Additional benefits include reduced consumer energy bills, and a cleaner environment (lower GHG emissions). Energy efficiency is the short-term solution

Manuscript received May 5, 2014; revised August 15, 2014.

The authors are with National Productivity Organization, Ministry of Industries \& Production, 2nd Floor Software Technology Park Constitution Avenue, F-5/1 Islamabad, Pakistan (e-mail: shermuhammadnioa@yahoo.com, shazia.shabbir0@gmail.com, usmannpo@gmail.com,wasi.elt92@yahoo.com). to the energy crisis.

\section{STUdy OBJECTIVES}

The sector wise energy consumption of Pakistan is:

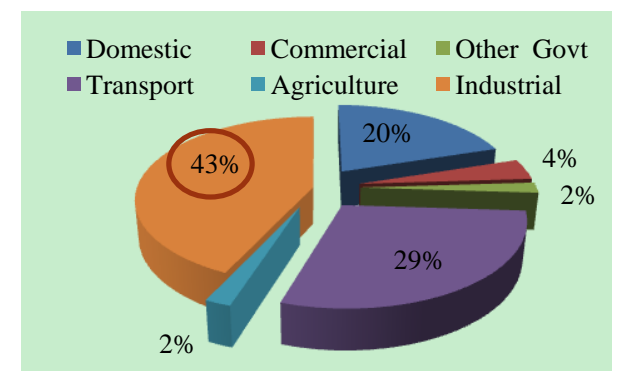

Fig. 1. Sector wise energy consumption.

Fig. 1 shows total energy consumption by sector in Pakistan, amounting to 39.4 million TOE (tonne of oil equivalent), $43 \%$ of which is accounted for by the industrial sector [3].

The industrial sector is the primary contributor to global final energy consumption which presents the biggest opportunity for savings at $33 \%$ of energy consumption and $38 \%$ of carbon dioxide $\left(\mathrm{CO}_{2}\right)$ emissions in 2005 [4]. Based on proven technologies it is estimated that industrial energy efficiency can be improved from $18-26 \%$ which results in reduction of industrial $\mathrm{CO}_{2}$ emissions by $19-32 \%$ [5]. Therefore, it is needed to focus on this sector in order to manage energy crisis.

National Productivity Organization (NPO), Ministry of Industries and Production, Pakistan, has established "Center for Energy \& Environment Management (CEEM)" to attain maximum efficiency in proper utilization of existing energy with the help of suitable energy saving measures that will contribute a major portion towards the productivity and economic growth of the country. The team of CEEM-NPO has conducted over 200 Energy Audits in industrial sector of Pakistan and identified up to $15 \%$ of energy savings potential.

This paper gives an overview of energy saving opportunities which they identified in Air conditioning units during different audits. And at the end of paper future steps followed by key findings and recommendations are proposed.

\section{A. Industrial Sector}

The industrial sector in Pakistan accounted for $20.9 \%$ of the GDP in FY2012-13, making it the second largest contributor to the economy after agriculture [6]. Industrial energy consumption in Pakistan is given below:

It can be seen from Fig. 2 that Textile Sector is third largest 
energy consumption industrial sector. It is one of the major export oriented industry and it adds up to $57 \%$ of the GDP, it was selected for research and development. Textile sector contains following sub sectors: Ginning, Spinning, Weaving, Processing, Knitting, Stitching, Garments

For further studies spinning sector was selected as major subsector of textile sector.

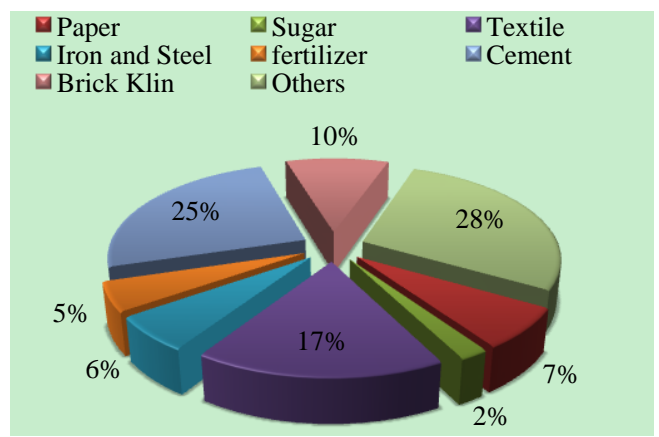

Fig. 2. Industrial energy consumption.

\section{Methodology}

In support of the above objectives, the NPO is undertaking energy audits to determine techno-economically feasible measures suitable to enhance productivity and reduce cost and consumption of energy at the designated textile units.

In the back drop of intimidating resource constraints, rising energy crises and big gap in demand and supply, the overall objective of the audit is to review the existing energy consumption practices in the industry, identify the key potential energy efficiency and conservation areas and provide detailed recommendations on energy optimization and cost savings. It aims to improve the competitiveness of textile sector on a sustainable basis by significantly reducing the cost of energy by developing energy management systems (EMS) \& imparting practical training to the technical staff of the industries.

\section{A. Audit Methodology}

- Informal Meeting with Management

- Plant Familiarization

- Walk Through

- Data Collection through interviews, observations \& trials

- Calculations

- Data Analysis

- Benchmarking

- Discussions

- Suggestions

\section{B. Energy Auditing Instruments}

NPO has used following energy-auditing instruments during the audits as and when required.

- $\quad$ Power Quality Analyzer

- Power Logger

- Lux Meter

- Flue Gas Analyzer

- Thermal Imager

- Infra Red Gun
- Digital vane Probe Anemometer
- $\quad$ Pitot Tube

- $\quad$ Fluke 922/Kit , Fluke 922 Airflow Meter

\section{DATA Collection}

Spinning sector is an export oriented sub-sector. It works as backbone in textile sector. During Energy Audits data was collected and analyzed of the entire Spinning unit including following departments:

1) Blow Room department

2) Carding department

3) Drawing/Combing/Roving department

4) Simplex department

5) Ring department

6) Auto cone department

7) Packing department

8) Compressor

9) Air Conditioning

\section{A. Energy Source}

Energy in most of industries is supplied by WAPDA (The Water and Power Development Authority) and in house Power Generation.

\section{B. Electrical Energy}

Electricity is the major energy on which all the spinning machines are dependent.

\section{Overview of Energy Consumption}

Average electricity consumption per day in a Textile Spinning sector is as under:

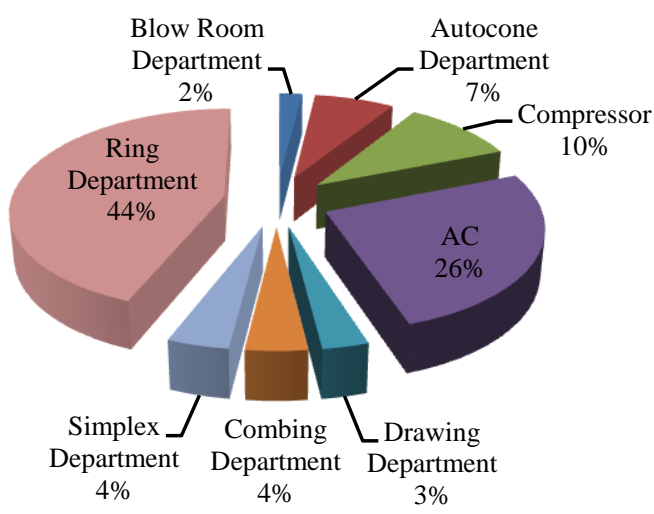

Fig. 3. Energy consumption in spinning sector.

According to the Fig. 3, air conditioning system is the second largest energy consumer and an important part of the mill. As per observations ACs is being running through conventional methods, which mostly results in low process performance. Therefore, in order to find out opportunities for improvements it was selected for further research studies.

\section{DATA ANALYSIS}

Air conditioning units are operated for the following purposes:

1) Attain required relative humidity in the production halls. Fiber and yarn requires certain moisture otherwise there are chances of their quality deterioration 
2) Remove the heat produced by the machines to avoid overheating and to keep them at lower possible temperature

3) Remove air contamination (fine fibers) present in the production halls

4) Maintain comfortable temperature inside the working areas for the workers

5) Humidity is controlled by maintaining the required wet and dry bulb temperatures in the production halls. Wet and dry bulb temperatures are selected on the basis of required humidity.

Detailed data of electric loads, air velocity, temperature, relative humidity was collected during audits. Departmental wise AC loading is given in Fig. 4:

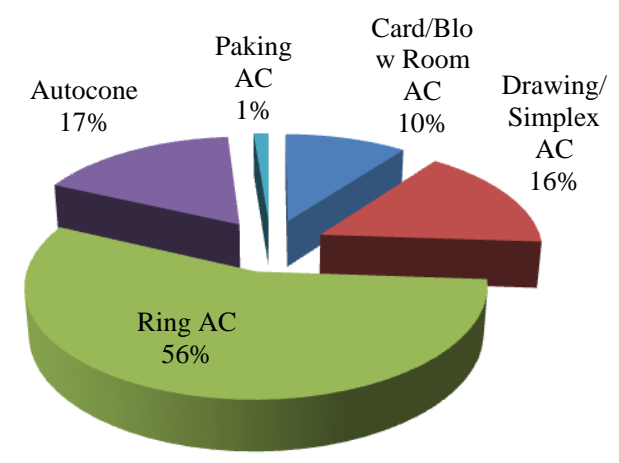

Fig. 4. Departmental AC loading.

There are three elements of Air Conditioning unit which plays important role. Average running load of return fan, water pump and supply fan is shown in Fig. 5.

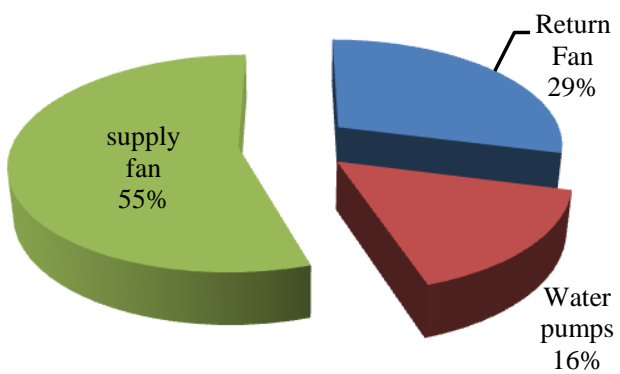

Fig. 5. AC-Running load.

\section{A. Supply Fan}

It transfers the reconditioned air to production hall as per need of the process. Its major elements are: electric fan motors, blades, ducts (through which air travels) and lowers (which equal distributes the air). Clean and humid air is necessary for production process, if it is disturbed then production losses increases, human irritation increases which may lead to high turnover and low productivity.

Department wise data of all supply fans were collected and analyzed as in Fig. 6.

\section{B. Return Fan}

It exhausts dirty and fluffy air from production hall which is then filtered, exhausted or reticulated after humidification. If it is not maintained properly than it does not exhaust dust air, due to which internal dust increases that results in low production and quality.

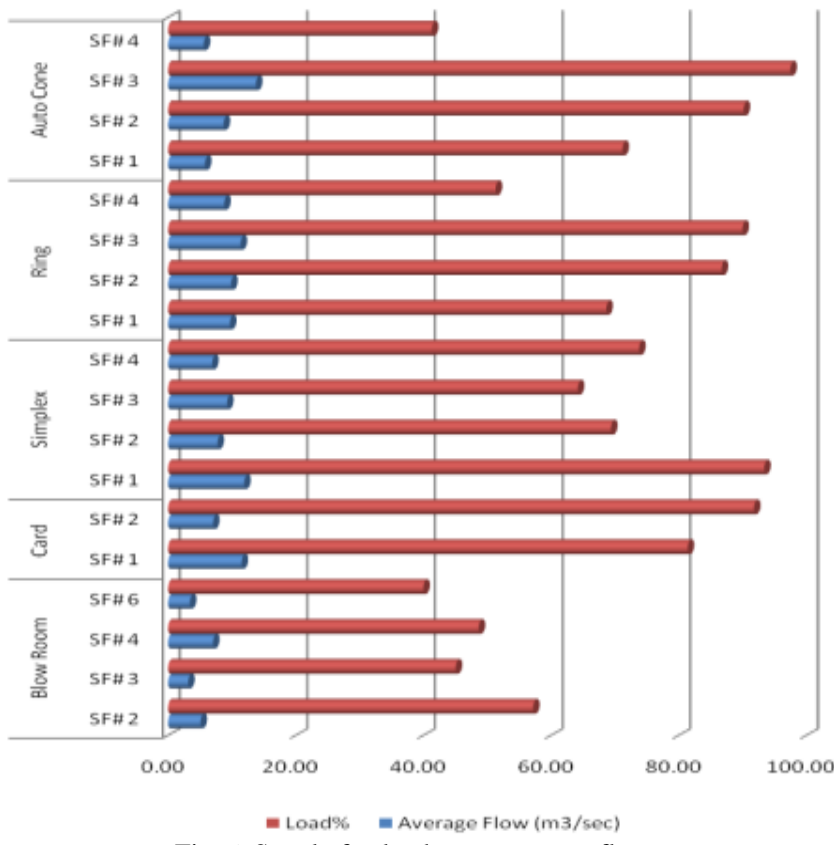

Fig. 6. Supply fan load \% vs. average flow.

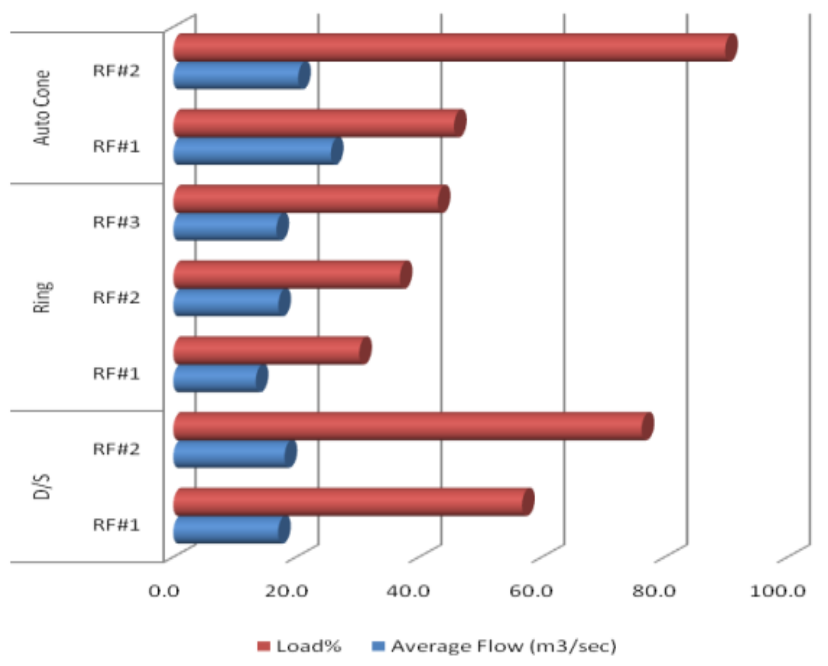

Fig. 7. Return fan load \% vs. average flow.

High variation between power consumption and air flow can be seen in Fig. 6 and Fig. 7, which is caused by lack of management, under skilled labour and conventional methods. This shows that we need technological interventions and technical expertise.

\section{Showering Chamber}

TABLE I: CONSUMPTION PATTERNS OF SHOWERING CHAMBER

\begin{tabular}{|l|c|c|c|}
\hline Departments & Carding & Drawing/Simplex & Ring \\
\hline Pump Capacity & 15 & 22 & 22 \\
\hline Running kW & 8.89 & 13.6 & 14.5 \\
\hline Total Nozzles & 176 & 176 & 176 \\
\hline Closed Nozzles & 70.4 & 65 & 60 \\
\hline Opened Nozzles & 105.6 & 111 & 116 \\
\hline Losses\% & 40 & 37 & 34 \\
\hline Losses $\mathrm{kW} / \mathrm{hr}$ & 6 & 9 & 9 \\
\hline
\end{tabular}

Showering chamber is an important part of an air conditioning system because it maintains the humidity of the production halls. Its main elements are water pump and nozzles. Water pumps pushes water towards nozzles and nozzles creates the fog. Proper maintenance of both elements is necessary because if the showering nozzles are blocked 
then it can turn into major energy loss and low productivity \& quality of the system as shown in Table I.

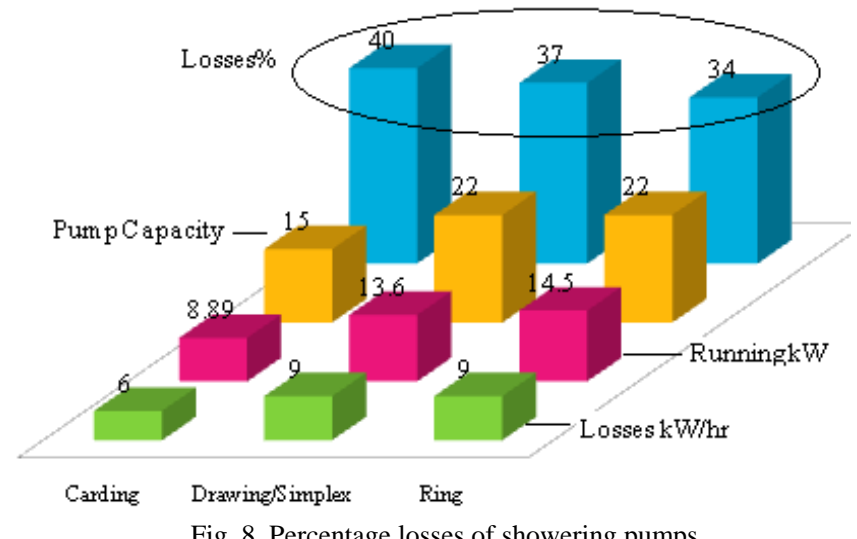

From Fig. 8 we can see that pump is not utilizing its full capacity due to which losses are beard. Therefore, in order to minimize losses proper maintenance is required.

\section{Case Studies}

1) Supply Fans: During the case study, supply fan no. 03 was running while in first case all other fans were off. In second case $02 \& 04$ were off. The difference between the flow and load is given in Table II:

TABLE II: SIMPLEX SUPPLy CHAIN CASE STUDY

\begin{tabular}{|c|c|c|c|}
\hline Supply fan \# & $\begin{array}{l}\text { Motor capacity } \\
(\mathrm{KW})\end{array}$ & Status & $(\mathrm{m} 3 / \mathrm{hr} / \mathrm{kW})$ \\
\hline \multirow{9}{*}{3} & \multirow{9}{*}{7.5} & \multirow{3}{*}{$\mathrm{ON}=\mathrm{ALL}$} & 1806.2 \\
\hline & & & 3235.3 \\
\hline & & & 1753.6 \\
\hline & & \multirow{3}{*}{$\mathrm{OFF}=\mathrm{ALL}$} & 11161.5 \\
\hline & & & 5164.3 \\
\hline & & & 2840.8 \\
\hline & & \multirow{3}{*}{$\mathrm{OFF}=2 \& 4$} & 5793.0 \\
\hline & & & 2956.8 \\
\hline & & & 1679.6 \\
\hline
\end{tabular}

2) Return Fans

$$
\text { (m3/hr) - Load\% }
$$

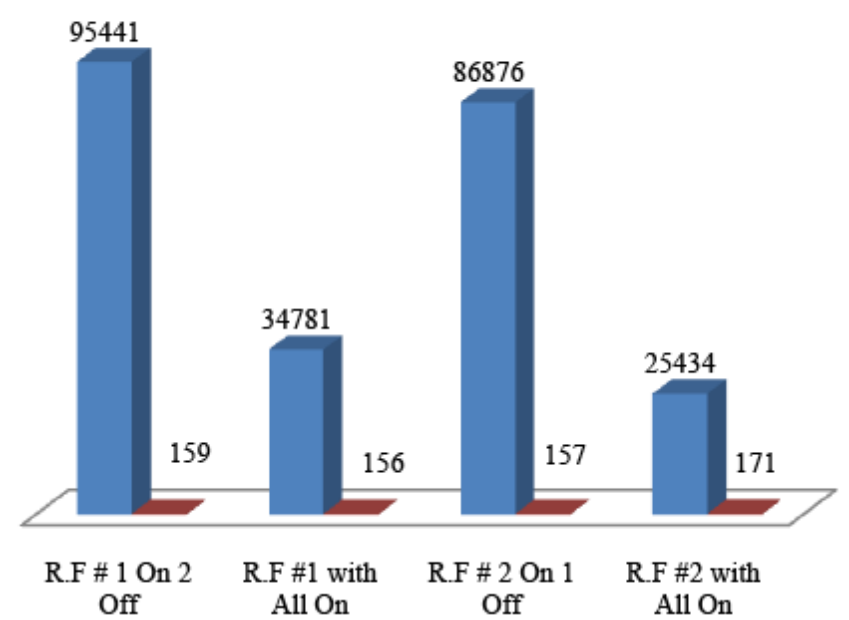

Fig. 9. Return fan case study Vs running flow.

The case studies of return and supply fans (Table II and Fig. 9) show that the system is not supporting the fan system to utilize it at maximum level. Proper research of infrastructure should be done to support maximum utilization of the fans. 3) Water pumps

TABLE III: WATER PUMP LOAD PERCENTAGE

\begin{tabular}{|c|c|c|c|}
\hline $\begin{array}{c}\text { Motor Capacity } \\
\text { kW }\end{array}$ & $\begin{array}{c}\text { Valve } \\
\text { Position }\end{array}$ & Total kW & Load \% \\
\hline \multirow{3}{*}{16} & $10 \%$ & 8.3 & 52 \\
\cline { 2 - 4 } & $50 \%$ & 12.93 & 81 \\
\cline { 2 - 4 } & $100 \%$ & 13.8 & 86 \\
\hline \multirow{3}{*}{18.5} & $10 \%$ & 3.32 & 18 \\
\cline { 2 - 4 } & $50 \%$ & 10.86 & 77 \\
\cline { 2 - 4 } & $100 \%$ & 16.9 & 91 \\
\hline
\end{tabular}

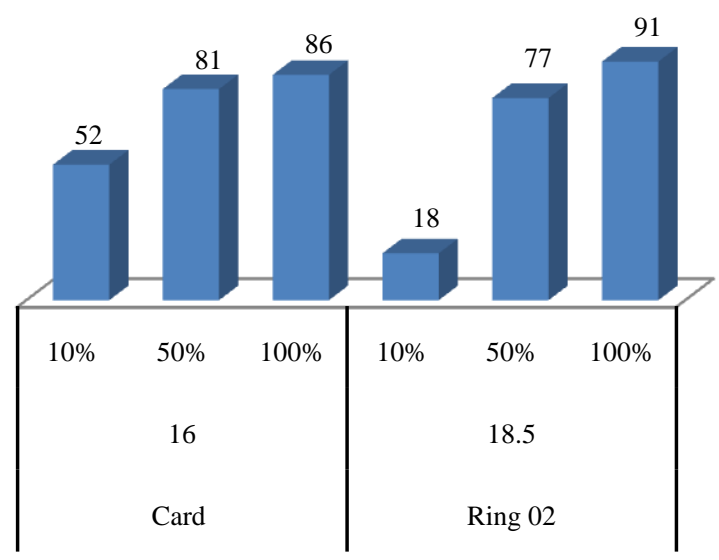

Fig. 10. Water pump load percentage.

We control the humidity in different times and seasons through wall throating due to which the output decreases while input energy almost remains same which leads to high specific consumption shown in (Table III and Fig. 10). So it is recommended a technological intervention may be done on mass level like mist system, inverters.

\section{FINDINGS / OBSERVATIONS}

During audits it was observed that air conditioning units are usually controlled by the following ways:

1) Decrease or increase flow of the air by changing the fan vanes angles (only for the variable fans). These angles are not being changed.

2) Discharge flow rate of water pump used for water showering is increased or decreased by throttling valve, depending on the humidity requirement

3) Supply, return and exhaust air dampers are manually controlled (opened or closed) according to the air quality and flow requirement.

4) Air flow is only controlled on the basis of humidity. There is no monitoring of volumetric air flow.

5) At some of the air conditioning units, there is water showering nozzles were blocked due to dust and scale.

Key Points to improve Air Conditioning System in textile sector of Pakistan.

- Lack of energy efficient infrastructure.

- Use of conventional infrastructure.

- Requirement of Research and development.

- Lack of innovation.

- Skill and capacity buildings.

- Proper management is required.

- Unrealistic supply to meet the demand which leads to major resource wastage. 
- Temperature loss in ducts in summer season due to improper insulation.

- Duct's internal rough conventional infrastructure losses humidity and dry the air supplied so more showering is required to meet the demand which leads to energy bills.

- Any variation in the supply air property leads to production loss and quality loss and also the human resource get irritated and its productivity decreases, it increase tension between management and labour force and decreases the final profit ratio and it could be the way to lose skilled man power

\section{RECOMMENDATIONS}

\section{A. General Recommendations}

1) We need to work on heat generation from equipments and other resources used in the production hall.

2) We need to have a tree plantation outside the AC unit to filter the air and protect it from sunlight, which is low cost solution rather than adding additional equipments.

3) Proper adjustment of lowers should be done for the even distribution of air.

4) It is recommended to optimize the air flows on the basis of humidity and air change requirements by changing air flows with the help of inverters. About $2 \%$ reduction in air flow will reduce $5 \%$ of the fans powers $(1.6 \%$ of total electricity will be reduced).

5) The system of operation to change the degree should be replaced with Variable Frequency Drive (VFD) so that air flow could be reduced by changing their frequency. Air flow control with inverters is more energy efficient way.

6) A showering chamber contains water nozzles. Water nozzles are more efficient way of increasing humidity and decreasing air temperature. It is recommended to maintain proper housekeeping of units with water nozzles.

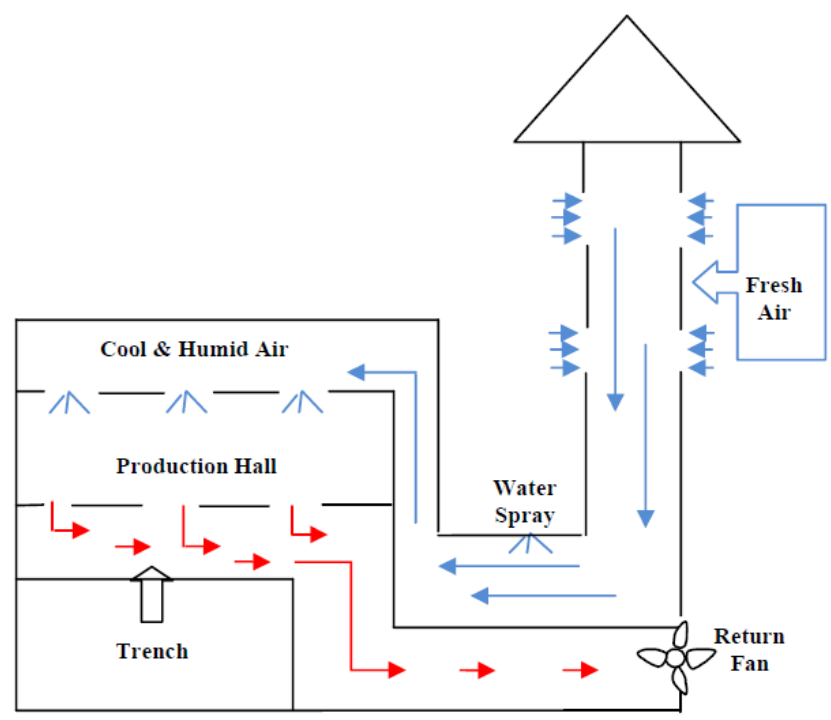

Fig. 11. Wind tower.

\section{B. Specific Recommendation}

NPO recommends to build wind tower building infrastructure (Fig. 11). Air changes can be managed by return fans supported by supply fans and the process requirements e.g. humidity, temperature etc may also be managed by direct humidification. In this way we can reduce some percentage of supply fan load, resulting in the reduction of power consumption.

\section{CONCLUSION}

The main objective of this study was to increase the efficient use of energy and to find opportunities for the conservation of the energy in the spinning subsector of textile industry. And also to indicate the key challenges in order to improve energy efficiency in air conditioning unit. It can be concluded here that their consumption can be minimized by improving efficiency, building infrastructure, and introducing control systems like VFD, sensors.

During the study energy consumption of air conditioning units was observed. On the basis our analysis, a number of recommendations have been made in this paper. After applying those recommendations we can save a lot of energy from each focused areas. For air conditioning units, $20 \%$ of the energy can be saved by implementing the suggested modifications.

Implementation of new intervention i.e. "wind tower" and a proper Energy Management System (EnMS) in industries and awareness on energy efficiency can add remarkable value in reducing the energy crises in Pakistan.

\section{REFERENCES}

[1] Issue Paper on 'Environment, Energy and Cities: Issues, Problems and Strategic Options for Urban Settlements of the Developing World', UN Habitat for a Better Urban Future, 24 May, 2005.

[2] J. J. McCarthy, O. F. Canziani, N. A. Leary, D. J. Dokken, and K. S. White, Climate Change 2001: Impacts, Adaptation and Vulnerability, Cambridge University Press, Cambridge, United Kingdom and New York, Inter-Governmental Panel Climate Change IPCC, 2001.

[3] Pakistan Energy Year Book, FY 2011-2012.

[4] International Energy Agency (IEA). (2008). Worldwide Trends in Energy Use and Efficiency Key Insights from IEA Indicator Analysis. IEA publications. [Online]. Available: http://www.iea.org/publications/freepublications/publication/name,37 78,en.html

[5] International Energy Agency (IEA). (2007). Tracking Industrial Energy Efficiency and $\mathrm{CO}_{2}$ Emissions. IEA. OECD Publishing, Publication. [Online]. Available: http://www.iea.org/publications/freepublications/publication/name,37 08,en.html

[6] Pakistan Economic Survey, FY 2012-13.

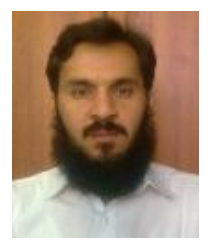

Aftab Khan Masood was born in South Waziristan Pakistan in 1981. He has a B.Sc. degree in textile engineering from National Textile University Faisalabad. Pakistan,

Currently he is working as a team leader of CEEM Department of National Productivity Organization (NPO) in Pakistan. He has 8 years of professiona experience in Energy Efficiency, and has, over the past 8 years, focused his work to the field of energy efficiency \& energy conservation area. He has done more than 100 energy audits and made significant contributions.

Mr. Khan is a member of the Pakistan Engineering Council.

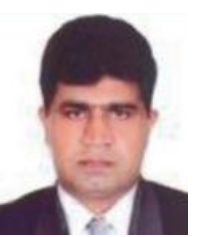

Sher Muhammad was born in Sargodha Pakistan in 1971. He has a Ph.D. degree in soil sciences from University of Kassal, Germany in 2005. He has done M.Sc. (Hons) in soil sciences from University of Agriculture Faisalabad, Pakistan in 1995 and B.Sc. (Hons) in soil sciences from University of Agriculture Faisalabad, Pakistan in 1993. 
Currently he is working as a chief executive officer at National Productivity Organization (NPO) in Pakistan. He has vast experience in supervising projects regarding green energy initiatives. He has more than 35 publications and presented 12 papers in conferences/seminars. His previous research disciplines of interests were related to soil and water conservations and currently his interests are related to energy efficiency in agricultural and industrial sectors.

Dr. Muhammad is a member of the Soil Sciences Society of Pakistan, Pakistan Botanical Society and Zoology Society of Pakistan.

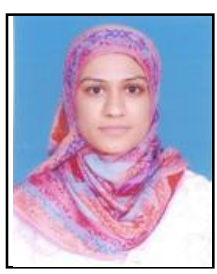

Shazia Iftikhar was born in Sindh Pakistan in 1987 She has a B.E. degree in electrical engineering from University of Engineering \& Technology UET, Taxila, Pakistan in 2010 and M.Sc. degree in engineering management from University of Engineering \& Technology UET, Taxila, Pakistan, 2012.

Currently she is working as a management associate in CEEM department of National Productivity Organization (NPO) in Pakistan. She has 3 years of professional experience in Energy Efficiency, and has worked as a team member in energy auditing projects.

Mrs. Iftikhar is a member of the Pakistan Engineering Council.

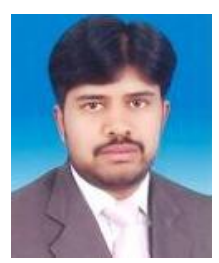

Hammad Altaf was born in Abbottabad Pakistan in 1987. He has a B.E. degree in electrical engineering from COMSATS Institute of Information Technology CIIT, Abbottabad, Pakistan in 2010.

Currently he is working as a management associate in CEEM Department of National Productivity Organization (NPO) in Pakistan. He has 4 years of professional experience in energy efficiency, and has conducted more than 60 energy audits of different industrial sectors of Pakistan.

Mr. Altaf is a member of the Pakistan Engineering Council.

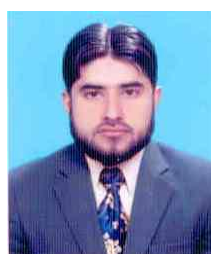

Wasi Ullah was born in Charsadda Pakistan in 1989. $\mathrm{He}$ has a B.Tech. degree in electrical engineering from Federal Urdu University of Arts Sciences and Technology PIMSAT, Lahore, Pakistan.

Currently he is working as a management trainee in CEEM Department of National Productivity Organization (NPO) in Pakistan. He has 3 years of professional experience in Energy Efficiency, and has conducted more than 50 energy audits of different industrial sectors of Pakistan.

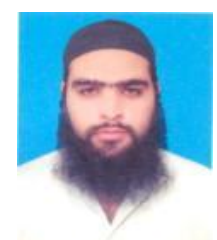

Faisal Shabbir was born in Islamabad Pakistan in 1989. He has a diploma in electrical engineering from Rawalpindi Swedish Institute of Technology, Rawalpindi, Pakistan.

Currently he is working as a management trainee in CEEM Department of National Productivity Organization (NPO) in Pakistan. He has 2 years of professional experience in energy efficiency, and has conducted more than 25 energy audits of different industrial sectors of Pakistan. 